\title{
A sticky information Phillips curve for South Africa
}

\author{
MONIQUE REID AND GIDEON DU RAND
}

Stellenbosch Economic Working Papers: 22/13

KEYWORDS: SOUTH AFRICA, STICKY INFORMATION, PHILLIPS CURVE

JEL: E31, E3, E52

MONIQUE REID DEPARTMENT OF ECONOMICS UNIVERSITY OF STELLENBOSCH

PRIVATE BAG X1, 7602

MATIELAND, SOUTH AFRICA

E-MAIL: MREID@SUN.AC.ZA
GIDEON DU RAND DEPARTMENT OF ECONOMICS UNIVERSITY OF STELLENBOSCH

PRIVATE BAG X1, 7602 MATIELAND, SOUTH AFRICA E-MAIL: GIDEONDURAND@SUN.AC.ZA

A WORKING PAPER OF THE DEPARTMENT OF ECONOMICS AND THE BUREAU FOR ECONOMIC RESEARCH AT THE UNIVERSITY OF STELLENBOSCH 


\title{
A sticky information Phillips curve for South Africa
}

\author{
MONIQUE REID*AND GIDEON DU RAND ${ }^{\dagger}$
}

\begin{abstract}
Mankiw and Reis (2002) propose the Sticky Information Phillips Curve as an alternative to the standard New Keynesian Phillips Curve, to address empirical shortcomings in the latter. In this paper, a Sticky Information Phillips curve for South Africa is estimated, which requires data on expectations of current period variables conditional on sequences of earlier period information sets. In the literature the choice of proxies for the inflation expectations and output gap measures are usually not well motivated. In this paper, we test the sensitivity of model fit and parameter estimates to a variety of proxies. We find that parameter estimates for output gap proxies based either on a simple Hodrik-Prescott filter application or on a Kalman filter estimation of an aggregate production function are significant and reasonable, whereas methods employing direct calculation of marginal costs do not yield acceptable results. Estimates of information updating probability range between 0.69 and 0.81 . This is somewhat higher than suggested by alternative methods using micro-evidence $(0.65-0.70$ (Reid, 2012)). Lastly, we find that neither parameter estimates nor model diagnostics are sensitive to the choice of expectation proxy, whether it be constructed from surveyed expectations or the ad hoc VAR based forecasting methods.
\end{abstract}

Keywords: South Africa, sticky information, Phillips curve JEL codes: E31, E3, E52

Note: This paper is also available as ERSA Working Paper 381. The authors acknowledge financial support for this project from Economic Research Southern Africa.

\footnotetext{
* Department of Economics, Stellenbosch University.

${ }^{\dagger}$ Department of Economics, Stellenbosch University.
} 


\section{INTRODUCTION}

The relationship between inflation and unemployment has both captivated and frustrated macroeconomists since the time of Hume (1752). In an agenda setting paper, Mankiw (2001) described the Phillips Curve as 'inexorable' claiming that, unless the trade-off between inflation and unemployment is acknowledged, it is impossible to explain the business cycle and short run effects of monetary policy. Similarly, Akerlof (2001: 375) declared that the Phillips Curve is 'the single most important macroeconomic relationship'.

Views about this trade-off cannot be separated from those regarding the appropriate role for monetary and fiscal policy (Mankiw (2001), Friedman (1968, 1976)). Ensuring economic stability is one of the primary objectives of macroeconomic policy, so the importance of understanding the Phillips Curve relationship is difficult to overstate.

However, despite this central role of this Phillips Curve, it is not yet fully understood. In his 1995 Nobel Lecture, Robert Lucas lamented that although so much research effort had already been dedicated to understanding the topic and so much evidence was available, economists still did not satisfactorily understand the impact of monetary policy on inflation and unemployment. The theory and empirical evidence about the long run were clear and convincing, yet the short run dynamics toward this long run were still the focus of much academic research. The primary contribution of the research in the 1970s (for which Lucas earned the Nobel Prize) was to focus attention on the micro-foundations of the Phillips Curve. It was found that the impacts of anticipated and unanticipated changes in monetary policy were notably different (Lucas, 1995).

The New Keynesian Phillips Curve (NKPC) is used today as the workhorse model, but Mankiw (2001) argues that despite its strengths, this model, too, is inadequate. Mankiw and Reis (2002) propose the Sticky Information Phillips Curve as an alternative to the standard New Keynesian Phillips Curve, in order to address empirical shortcomings in the latter. In this paper, a Sticky Information Phillips Curve for South Africa is estimated, which requires data on expectations of current period variables conditional on sequences of earlier period information sets. In the literature the choice of proxies for the inflation expectations and output gap measures are usually not well motivated. In this paper, we therefore test the sensitivity of model fit and parameter 
estimates to a variety of proxies. We find that parameter estimates for output gap proxies based either on a simple Hodrik-Prescott filter application or on a Kalman filter estimation of an aggregate production function are significant and reasonable, whereas methods employing direct calculation of marginal costs do not yield acceptable results. Estimates of information updating probability range between 0.69 and 0.81 . This is somewhat higher than suggested by alternative methods using micro-evidence (0.65 - 0.70 (Reid, 2012)). Lastly, we find that neither parameter estimates nor model diagnostics are sensitive to the choice of expectation proxy, whether it be constructed from surveyed expectations or the ad hoc VAR based forecasting methods.

The NKPC and Mankiw's criticism thereof are presented in section 2. This is followed in section 3 by a discussion of the Sticky Information Phillips Curve (SIPC) which Mankiw and Reis $(2002,2003)$ offer as an alternative to the NKPC. After a brief summary of the progress made through modelling the Phillips Curve in South Africa, the paper turns to the estimation of the SIPC for South Africa.

A full comparative evaluation of the NKPC relative to the SIPC for South Africa is beyond the scope of this paper, as our investigations revealed a lack of clarity in the South African literature on the appropriate methods and proxies to use. We explore in detail the available variations in data sources and estimation approaches and evaluate the model fit implications of the various options: Section 4 discusses the data challenges and section 5 presents the results and sensitivity analyses. Section 6 compares the results to other estimates as well as international literature and section 7 concludes.

\section{THE NEW KEYNESIAN PHILLIPS CURVE}

The NKPC has become accepted as the workhorse model in dynamic stochastic general equilibrium models (McCallum, 1997). It is derived from micro-foundations that hinge on the assumption that monopolistically competitive firms with some pricing power do not always update their prices in response to new information obtained in a specific period. This causes a nominal rigidity in the form of price persistence and yields a negative sloping Phillips Curve (the slope is called "negative" as it refers to the short run relationship between unemployment and inflation, but since most models are now written in terms of the output gap, the slope coefficient in the central equation is positive), formulated as: 


$$
\pi_{t}=\left[\alpha \lambda^{2} /(1-\lambda)\right] y_{t}+E_{t} \pi_{t+1}
$$

where, $\pi_{t}$ is the inflation rate, $y_{t}$ the output gap and $\lambda$ the fraction of firms that update their prices in a given period. The parameter $\alpha$ measures the degree of real rigidity (sensitivity of the optimal relative price to the current output gap, due to imperfect competition)

However, Mankiw (2001) labelled the Phillips Curve not only 'inexorable', but also 'mysterious', due to the inability of the model to match the observable reality. Mankiw (2001) identified three related properties of the NKPC, which he argued rendered it fundamentally flawed. First, observed inflation is highly persistent (Fuhrer and Moore, 1995). The NKPC does not reflect this, since the sticky price assumption in the NKPC does not necessarily result in sticky inflation. Second, the NKPC model predicts that disinflationary monetary policy need not be contractionary and could even cause an economic boom if the central bank is credible (Ball, 1994); empirically, however, disinflations mostly seem to come at the cost of some degree of contraction. Some extensions of the NKPC have been offered to mitigate these shortcomings, such as the suggestion by Fuhrer and Moore (1995) that backward looking expectations be included in the model to generate persistent inflation, to match that observed. However, Mankiw (2001) finds none of these convincing ${ }^{1}$ and believes that they fail to address the underlying problem. He argues, thirdly, that the implausible impulse response functions of the NKPC model illustrate the problem most clearly:

"Although the new Keynesian Phillips Curve has many virtues, it also has one striking vice: It is completely at odds with the facts. In particular, it cannot come even close to explaining the dynamic effects of monetary policy on inflation and output."

(Mankiw, 2001:52)

The Phillips Curve is crucial to our understanding of the business cycle and should capture the broad consensus that there is a trade-off between inflation and unemployment in the short run, but not in the long run. It is central to monetary policy analysis as it describes the time-varying

\footnotetext{
${ }^{1}$ For example, Fuhrer and Moore's (1995) inclusion of backward looking expectations in their model to produce inflation persistence can be considered to be somewhat ad hoc as it is not the outcome of an optimising decision of an agent in the model, and therefore may not be justified as a coherent part of the general equilibrium that leads to the rational expectations forward looking Phillips Curve.
} 
effects of monetary policy. Therefore criticism of the NKPC's ability to model the dynamic effects of monetary policy on the economy has serious implications.

\section{THE STICKY INFORMATION PHILLIPS CURVE}

Mankiw and Reis (2002) proposed the Sticky Information Phillips Curve (SIPC) as an alternative to the NKPC based on different assumptions on the microeconomic origins of nominal rigidity. As a plausible alternative to the contentious assumption that firms cannot adjust their own prices at will, they assume that information acquisition is neither perfect nor instantaneous. Stated differently: Rather than assuming that only a fraction of firms are "allowed" or "able" to adjust their prices even when all are aware of the fact that the desired price is different from the current price (the typical Calvo pricing assumption - see Calvo (1983)), they assume that only a fraction of firms obtain information that implies a price change is necessary.

This is a more appealing assumption than both the original New Keynesian assumption and the more ad hoc extensions that have been proposed (e.g. Furher and Moore, 1995), as it corresponds directly to the problem that all businesspeople (and economists) face: Information on competitive forces and the current state of the economy are costly to obtain and often hard to interpret.

Unlike the sticky price model, the sticky information model is able to generate sticky inflation (inflation persistence) and it produces dynamics that better fit the stylised facts observed in the data (Mankiw and Reis, 2002).

The sticky information Phillips Curve they propose takes the following reduced form:

$$
\pi_{t}=[\alpha \lambda /(1-\lambda)] y_{t}+\lambda \sum_{j=0}^{\infty}(1-\lambda)^{j} E_{t-1-j}\left(\pi_{t}-\alpha \Delta y_{\mathrm{t}}\right)
$$

where the variables are defined as before, except that $\lambda$ is now the fraction of firms that update their information set (i.e. observe the shock/impulse) in a given period, and $\Delta y_{\mathrm{t}}$ is the change in the output gap.

The SIPC is also supported by micro-foundations. Before the introduction of the SIPC, Roberts (1997) recognised that sticky prices did not necessarily result in sticky inflation in the standard models. He argued that this could be explained either by assuming sticky inflation instead of 
sticky prices (conditional on rational expectations), or by assuming sticky prices and imperfectly rational expectations. Roberts (1997) concluded that relaxing the assumption of rational expectations was preferable, given that his survey-based evidence showed that inflation was not sticky. Carroll $(2002,2006)$ later proposed some micro-foundations for Mankiw and Reis' (2002, 2003) SIPC, which provides further evidence that the SIPC is able to model the observable macroeconomic data well. These micro-foundations have also been estimated for South Africa and the results are briefly discussed at the end of section 5 in order to provide support for the results in this paper.

\section{DATA CHALLENGES}

Obtaining the data required to estimate the SIPC forms a substantial part of the challenge faced by a researcher in this literature. To estimate the SIPC, the following data is required for each period: The current output gap, $y_{t}$, as well as the entire sequence of all previous expectations of current period inflation, $\left\{E_{t-j}\left(\pi_{t}\right)\right\}_{j=1}^{\infty}$, and output gap growth values, $\left\{E_{t-j}\left(\Delta y_{t}\right)\right\}_{j=1}^{\infty}$. Since none of these terms have obvious empirical counterparts, we discuss our choices in the following subsections.

\subsection{OUTPUT GAP MEASURE}

The output gap - the difference between actual output and potential output - is an inherently unobservable quantity that must be estimated in some manner. An output gap estimated using the Hodrik-Prescott (HP) filter is still commonly used even though it has been widely criticised in the literature. For instance, Du Plessis and Burger (2006) argue that smoothing the output using the univariate HP filter to estimate potential output would cause measurement error; since it is essentially a frequency filter that isolates low frequency variation, it would discard some relevant information. It does not incorporate information contained in other variables, such as the available labour force, capital stock or competitive nature of the economy, which clearly must be intimately linked with the productive potential that underlies the concept of the output gap.

No consensus exists as to what constitutes the best output gap measure, since all measures are to some extent driven by modelling assumptions. As such, we provide estimates of the SIPC using three different measures of the output gap: The standard HP-filter based measure, a direct 
calculation of marginal costs based on a model by Gali and Gertler (1999) and a Kalman filter estimation of an aggregate production function recently employed successfully for the South African economy by Kemp (2011). The HP-filter based output gap is standard - using the usual smoothing parameter of 1600 for quarterly data, and as such we discuss only the marginal cost measure and the Kalman filter measure in detail.

Gali and Gertler (1999) argue that using a measure of marginal costs rather than the output gap is both theoretically more sound and models the data more accurately when used in a Phillips curve. Theoretically, the link between the two primary variables in a Phillips Curve (inflation and the output gap) operates via the effect of real activity on marginal costs (Gali and LópezSalido, 2005). In addition, research (Sbordone (1999), Gali and Gertler (1999), and Gali, Gertler and López-Salido (2000)) has demonstrated that marginal costs are useful for explaining inflation dynamics in a number of countries. Under certain assumptions there is an approximate log-linear relationship between the output gap and marginal costs (Gali and Gertler, 1999). In this case the relationship between marginal costs and the output gap can be represented as:

$$
\widehat{m c}_{t}=\delta\left(r_{t}-r_{t}^{*}\right)
$$

where $r_{t}$ is the logarithm of real output and $r_{t}^{*}$ is the logarithm of the natural level of output (Gali and López-Salido, 2005). Therefore, $\left(r_{t}-r_{t}^{*}\right)$ is the output gap. However there is evidence that these conditions often do not hold (Gali and Gertler, 1999, du Plessis and Burger, 2006), which Gali and Gertler (1999) argue is one of the reasons that estimations of the Phillips Curve have had only limited success.

Although marginal costs are also unobservable they may be more amenable to accurate estimation than the output gap. Gali and Gertler (1999) suggested a way to derive an estimable version of the marginal costs from the production function. However, since South Africa is an open economy it is preferable to use an open economy extension of marginal costs (Gali and López-Salido, 2005):

$$
\begin{aligned}
& m c_{t}=s_{t}+\gamma\left(p m_{t}-w_{t}\right) \\
& \gamma=\left[\frac{1-\mu \omega}{\mu \omega}\right](\sigma-1)
\end{aligned}
$$


where $\sigma$ represents the import elasticity of the domestic production, $\mu$ the mark-up, $p m_{t}$ the $\log$ of import prices, $w_{t}$ the log of remuneration per worker, $\omega$ the steady state value of labour income share and $s_{t}$ real unit labour costs.

Data for import prices, remuneration per worker, and the labour income share are from the South African Reserve Bank. The mark-up and import elasticity of domestic production must be calibrated. We assume that the mark-up is 30\% (in line with Fedderke and Schaling (2005)), and that the elasticity of domestic production is 1 or 1.5 (in line with du Plessis and Burger (2006) and Gali and López-Salido, 2005). The Kalman Filter based measure of potential output is based on the direct estimation of a standard Cobb-Douglas production function for the South African economy using employment data obtained from various labour force surveys, and capital stock and GDP data from the South African Reserve Bank.

We estimate a constant returns to scale production function in logarithmic form, assuming that real output $\left(r_{t}\right)$, employment $\left(l_{t}\right)$ and capital stock $\left(k_{t}\right)$ are observable, but that total factor productivity $\left(a_{t}\right)$ is unobserved and follows a random walk with normal innovations $\left(v_{t}\right)$ and no drift $^{2}$. The simple 2 equation system estimated via a Kalman Filter is thus:

$$
\begin{aligned}
& r_{t}=a_{t}+\theta k_{t}+(1-\theta) l_{t}+u_{t} \\
& a_{t}=a_{t-1}+v_{t}
\end{aligned}
$$

The estimation of this system with quarterly data is not straightforward, but as it is not central to the concern of this paper, we relegate estimation details and comparisons to earlier work to appendix A1.

Our estimate of the capital share parameter $\theta$ is 0.59 , somewhat higher than other estimates for the South African economy that primarily use annual data of a longer and earlier sample. We use smoothed versions of the estimated total factor productivity, capital stock and potential employment as proxies of "potential" values of each of the production function inputs with our

\footnotetext{
${ }^{2}$ We deliberately choose to model total factor productivity (TFP) as having no drift, primarily as a theoretical matter: We impose that the aggregate expectation in the economy is that changes to TFP are entirely unpredictable. While this is a strong assumption, we feel that it is more representative of the uncertain times covered by our sample than the alternative - unconditionally expected growth in TFP - that would be implied by a positive drift term.
} 
estimated capital share parameter, to construct a production function based estimate of potential output. The difference between actual output and this estimate of potential output is then our Kalman Filter based output gap.

We compare the three output measures with one another, inflation, and the official turning points in the South African business cycle as identified by the South African Reserve Bank in Table I and Figure I, where officially identified recessions in this sample period are indicated by shaded areas.

Figure I: Three Output Gap Measures:

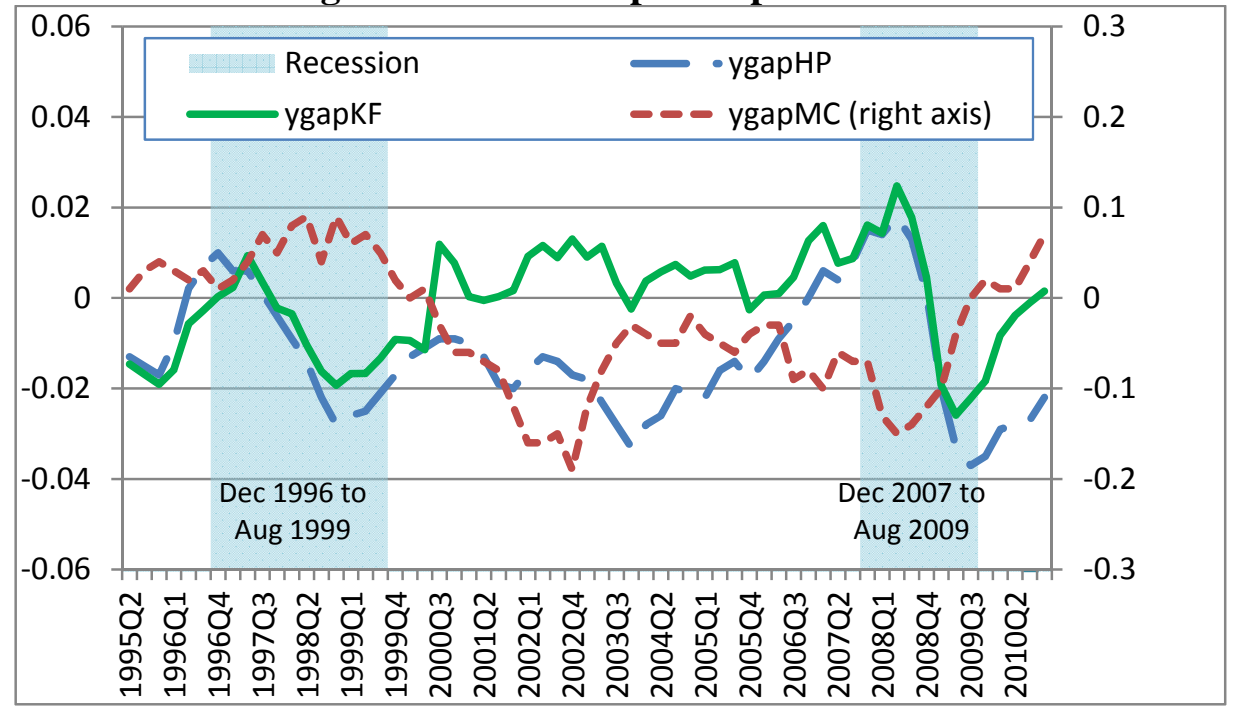

Table I: Contemporaneous Correlation Matrix of Inflation and Output Gap Measures over

\begin{tabular}{|l|r|r|r|}
\multicolumn{1}{c|}{ the whole sample } \\
\cline { 2 - 4 } \multicolumn{1}{c|}{} & ygapKF & ygapHP & ygapMC \\
\hline Inflation & -0.05 & 0.27 & -0.11 \\
\hline ygapKF & & 0.56 & -0.65 \\
\hline ygapHP & & & -0.24 \\
\hline
\end{tabular}

We note the following about the three measures:

The HP-filter based output gap (hereafter ygapHP) and the Kalman filter based output gap (hereafter ygapKF) do well in capturing the two downturns, showing uniform decline in the output gap from positive to negative territory, although the turning points suggest somewhat shorter recessions than the official dates. Since the SARB uses a data rich approach, this difference is not too severe considering the very short and narrow dataset we employed. The 
upturn between December 1999 and August 2007 seems to be better captured by ygapKF than ygapHP, as the latter shows a large fall during the boom while the former shows only smaller downward ticks. The relative performance of the two measures over this period corresponds well to the findings of Kemp (2011) over the same period, even though he uses annual data over a much longer sample (starting in the 70s).

The measure of marginal costs as a proxy for the output gap (hereafter ygapMC) appears not to work very well, if one takes the official cycle alone as the measure of performance. We provide estimation results for this measure in any event, since it is not obvious that this rough yard stick should be used in isolation to determine the validity of an output gap proxy for our purposes: The model we are estimating deals with information about inflation, not identification of the business cycle directly.

\subsection{EXPECTATIONS OF INFLATION AND CHANGES IN THE OUTPUT GAP}

The second term of the SIPC (equation 2), contains the sum of all lagged expectations into the infinite past of current period inflation and growth in the output gap. This paper considers both survey based and reduced-form forecast based measures of the expectations of inflation and the growth in the output gap in order to test whether the results are sensitive to the choice of proxy. One important challenge to overcome is that the expectations data is limited and therefore the expectations terms must be truncated at some reasonable horizon. The surveyed expectations are only available for a horizon of four quarters, whereas the models can be used to generate forecasts with longer horizons. For purposes of comparison we use four quarters of previous forecasts for all estimations as the truncation point.

\subsubsection{Bivariate VAR to forecast inflation and the output gap}

The most popular approach adopted in the literature on the SIPC is to use Stock and Watson's (2003) bivariate VAR to construct out-of-sample forecasts of inflation and the output gap. Stock and Watson (2003) tested the power of using asset prices (which are assumed to be forwardlooking and therefore to be informative about future economic developments) for short- to medium-term forecasting. They conclude that some asset prices have substantial predictive content, but that forecasts based on individual indicators as well as in-sample significance tests 
are potentially unstable. They thus recommend "simple methods for combining the information in the various predictors, such as computing the median of a panel of forecasts based on individual asset prices" (2003:789). More specifically, they propose that it would be preferable to use a simple combination (for example the median) of the out-of-sample forecasts of a set of bivariate VARs.

A concern that is raised about the Stock and Watson (2003) VAR based approach lies in the fact that the lag length of the bivariate VAR models must be chosen by the researcher. This creates temptation to select the 'best' lag length based on the ex post forecasting performance of each bivariate VAR against actually observed data (Kahn and Zhu (2006), for example, explicitly state that this was their approach). In the present context, where the expectation formation process is assumed to be conditional only on current and past data, this is greatly problematic: The agents whose expectation formation (by hypothesis) drives the dynamics of inflation, could not have done this ex post data comparison, hence no methodology that uses such ex post validation can be said to actually represent the behaviour of the agents modelled. We therefore strongly prefer the surveyed expectations approach as it was measured before the realisation of the variables in question, and hence could not have been data-mined in a untransparent manner. We discuss the survey based measures in the next subsection.

Facilitation comparability with other work on the SIPC, we also use the VAR based methodology, but to avoid the above mentioned 'data-mining' trap we select the appropriate VAR forecasting models not on ex post forecast performance, but on ex ante data congruency in the sense of Hendry and Nielsen (2007:302): A minimum requirement for a model to fit the data is that it should produce white noise residuals.

Two sets of bivariate VARs were estimated, one to forecast inflation and the other to forecast the change in the output gap. The variables used to forecast inflation and the output gap respectively, and some details about each are listed in Table II. 
Table II: Bivariate VAR Forecast models:

\begin{tabular}{|c|c|c|c|}
\hline $\begin{array}{l}\text { Measure to } \\
\text { be forecast }\end{array}$ & Variables & Details & Source \\
\hline \multirow[t]{6}{*}{ Inflation } & $\begin{array}{l}\text { Short-term } \\
\text { interest rate }\end{array}$ & $\begin{array}{l}3 \text { month Treasury Bill. South Africa } \\
\text { Reserve bank code: } 1405 \mathrm{~W}\end{array}$ & $\begin{array}{l}\text { South African Reserve } \\
\text { Bank (SARB) }\end{array}$ \\
\hline & Dividend Yield & & I-Net Bridge \\
\hline & Term Spread & $\begin{array}{l}\text { The difference between the } 3 \text { month } \\
\text { Treasury Bill rate and } 10 \text { year } \\
\text { government bond yields. }\end{array}$ & $\begin{array}{l}\text { Own calculation from } \\
\text { SARB codes: } 1405 \mathrm{~W} \text { and } \\
\text { 2003M. }\end{array}$ \\
\hline & $\begin{array}{l}\text { Unemployment } \\
\text { Rate }\end{array}$ & Various labour force surveys & $\mathrm{Yu}(2007)$ \\
\hline & $\begin{array}{l}\text { Capacity } \\
\text { Utilisation }\end{array}$ & $\begin{array}{l}\text { South Africa Reserve bank code: } \\
\text { 7078L }\end{array}$ & SARB \\
\hline & Output gap & $\begin{array}{l}\text { Separate Forecasts using each of the } \\
\text { three output gap measures in the } \\
\text { corresponding estimation. }\end{array}$ & $\begin{array}{l}\text { See section } 4.1 \text { and } \\
\text { appendix A }\end{array}$ \\
\hline \multirow[t]{6}{*}{ Output Gap } & $\begin{array}{l}\text { Short-term } \\
\text { interest rate }\end{array}$ & $\begin{array}{l}3 \text { month Treasury Bill. South Africa } \\
\text { Reserve bank code: } 1405 \mathrm{~W}\end{array}$ & SARB \\
\hline & Dividend Yield & & I-Net Bridge \\
\hline & Term Spread & $\begin{array}{l}\text { The difference between the } 3 \text { month } \\
\text { Treasury Bill rate and } 10 \text { year } \\
\text { government bond yields. }\end{array}$ & $\begin{array}{l}\text { Own calculation from } \\
\text { SARB codes: } 1405 \mathrm{~W} \text { and } \\
\text { 2003M. }\end{array}$ \\
\hline & $\begin{array}{l}\text { Stock } \quad \text { Market } \\
\text { Index }\end{array}$ & & I-Net Bridge \\
\hline & $\begin{array}{l}\text { Capacity } \\
\text { Utilisation }\end{array}$ & $\begin{array}{l}\text { South Africa Reserve bank code: } \\
\text { 7078L }\end{array}$ & SARB \\
\hline & Inflation & Quarter on Quarter & Statistics South Africa \\
\hline
\end{tabular}

We provide summary measures of these forecasts with comparisons to the surveyed expectations approach in section 4.2.3. 


\subsubsection{Bureau of Economic Research Quarterly Survey of inflation and growth expectations}

Our preferred measure of inflation expectations is obtained from the expectations surveys of the BER (Bureau for Economic Reseach, 2000-2010). Coibion (2010) argues that it is essential to have actual measures of past expectations as regressors (as opposed to simple, regression based forecast measures).

Other surveys of inflation expectations exist: The Reuters Econometer and Bloomberg surveys offer data of financial analysts' expectations of inflation and output. However, they only survey financial analysts. In Reid (2012), who provides micro-foundations for the SIPC being estimated in this paper, the case was presented that the expectations of financial analysts does not always accurately represent those of the non-financial market segments of the economy (the prices setters, who are responsible for a large proportion of the price-determining economic decisions within an economy). For this study we therefore prefer the BER's surveys (that cover a wide range of economic decision-makers) over those of Reuters and Bloomberg.

The BER surveys have one major drawback, however: The surveys are done every quarter, but the respondents are asked for their expectations of inflation and output (and a range of other macroeconomic variables) for the current and two following calendar years. Since the SIPC model requires quarter on quarter measures, we have to use a combination of identities that relate annual to quarterly expectations, and some assumptions on time series properties of these expectations, to extract the required data. The details of these calculations are given in appendix A2.

\subsubsection{Comparing VAR based and Surveyed Expectations}

Table III contains the Root Mean Square Forecast Error (RMSFE) for all the different options of output gap proxy and all the different lags of the expectation operator that enter our estimation. Since one of the set of forecasting variables for inflation using the Stock and Watson (2003) methodology is the estimated output gap, there is a different forecast of inflation for each of the different output gap measures we consider. 
Table III: Forecast Performance of the various proxies available RMSFE of Expectations of Inflation

(directly comparable across columns and rows)

\begin{tabular}{|c|c|c|c|c|}
\hline Expectation Proxy & Survey Based & \multicolumn{3}{|c|}{ Bi-Variate VAR based } \\
\hline $\begin{array}{c}\text { Output Gap Measure } \\
\text { used in Forecasts }\end{array}$ & & ygapMC & ygapHP & ygapKF \\
\hline$E_{t-1}$ & 0.0099 & 0.0097 & 0.0097 & 0.0093 \\
\hline$E_{t-2}$ & 0.0108 & 0.0109 & 0.0109 & 0.0103 \\
\hline$E_{t-3}$ & 0.0117 & 0.0111 & 0.0112 & 0.0107 \\
\hline$E_{t-4}$ & 0.0120 & 0.0117 & 0.0119 & 0.0114 \\
\hline
\end{tabular}

\section{RMSFE of Expectations of Change in Output Gap}

(not directly comparable across columns)

\begin{tabular}{|c|c|c|c|c|c|}
\hline Expectation Proxy & \multicolumn{2}{|c|}{ Survey Based } & \multicolumn{3}{|c|}{ Bi-Variate VAR based } \\
\hline $\begin{array}{c}\text { Output Gap Measure } \\
\text { used as “actual” values }\end{array}$ & $\begin{array}{l}\text { Output } \\
\text { Growth }\end{array}$ & ygapKF & ygapMC & ygapHP & ygapKF \\
\hline$E_{t-1}$ & 0.0079 & 0.0114 & 0.0307 & 0.0049 & 0.0069 \\
\hline$E_{t-2}$ & 0.0073 & 0.0102 & 0.0300 & 0.0060 & 0.0068 \\
\hline$E_{t-3}$ & 0.0070 & 0.0104 & 0.0305 & 0.0063 & 0.0069 \\
\hline$E_{t-4}$ & 0.0070 & 0.0107 & 0.0313 & 0.0064 & 0.0072 \\
\hline
\end{tabular}

While all the inflation expectations are compared to observed quarter on quarter inflation, rendering the RMSFE directly comparable across columns in the top panel of Table III, the same is not true for the output gap measure. For each column we are comparing expected values to the corresponding actual values of the different estimated output gap measures - the details of the comparisons are in the table.

\subsection{STATIONARITY}

Our inflation, output gap, marginal cost, and expectations of inflation and the output gap measures, were subjected to a range of tests for unit roots and stationarity. The Augmented Dicky Fuller (ADF) test is known to have low power, and the Phillips-Perron (PP) does not perform well in small samples (Davidson and MacKinnon, 2004). Therefore Dickey Fuller 
Generalised Least Squares (DF GLS) and Ng-Perron tests were also used, as they perform relatively better in small samples. The ADF test finds that marginal costs are non-stationary and the PP test finds that inflation and marginal costs each have a single unit root. However, in all other cases the variables used in our model are found not to contain a unit root. Since our sample is very short, however, we do not place much confidence in the unit root tests.

As a complement to the unit root tests that mostly rejected the null of a unit root in favour of the alternative of no unit root, we employed the Kwiatkowski, Phillips, Schmidt and Shin (1992) test (KPSS test) to test the null of stationarity against the alternative of a unit root $^{3}$. The KPSS test tends to be sensitive to the number of autoregressive lags included in the test regression - the greater the number of lags included, the more likely that the null hypothesis will be not be rejected. In all but one case, however, the tests gave evidence in favour of level-stationarity for all variables that enter our estimation when controlling for only one lag in the test regression (many were stationary even with no autoregressive element). The sole exception was again the ygapMC and a few of its related expectation terms, but even here a relatively parsimonious 3 autoregressive terms in the test regression was enough for the test to conclude that the variable was level stationary at the $2.5 \%$ level.

As a last natural test, we check that the residuals of the estimations are white noise - in all estimations that yielded our preferred estimates, this was achieved with no differencing or other ex ante attempts to render the data stationary.

\section{EMPIRICAL EVALUATION}

\subsection{SAMPLE AND ECONOMETRIC METHOD}

The main sample used to estimate the SIPC in this paper is 2000Q3 to 2010Q4. Two issues arise with regards to the estimation of this single equation: Firstly, the estimation of the SIPC requires the calibration of real rigidity (alpha). In this paper we set this value to 0.1 , in line with Kahn and Khu (2006) and Mankiw and Reis (2002). Future work will provide robustness checks as to the impact of this for plausible ranges of this parameter.

\footnotetext{
${ }^{3}$ We thank an anonymous referee for suggesting this necessary complementary approach.
} 
Secondly, the output gap is likely to be endogenous in the estimation (Coibion, 2007). Although lags of variables entering the estimation can be used as potential to address this concern in the case of the NKPC (as was done in du Plessis and Burger (2006)), Coibion argues that the necessary truncation of the infinite summation lessens the effectiveness of lagged variables as instruments, and some endogeneity may remain. As this is likely to bias the coefficient upwards, we therefore use lagged output gap measures and lags of expectation terms as instruments, following Coibion (2007), and provide Hansen's J-test of over-identifying restrictions to evaluate whether the instruments seem plausible.

We use a generalised method of moments (GMM) approach to estimate the single parameter of interest, as the specification is highly non-linear in the parameter. This methodology is standard for these types of problems, and is described in detail in Hamilton (1994). Here we provide only a brief outline.

Truncation (as well as measurement error) implies that the estimable version of the SIPC has a stochastic component:

$$
\pi_{t}=[\alpha \lambda /(1-\lambda)] y_{t}+\lambda \sum_{j=0}^{4}(1-\lambda)^{j} \hat{E}_{t-1-j}\left(\pi_{t}-\alpha \Delta y_{\mathrm{t}}\right)+\varepsilon_{t}
$$

Assuming that lagged right hand side variables are independent of the current error term allows the following set of moment conditions to be used in the GMM procedure:

$$
E\left[\mathbf{x}_{t} \varepsilon_{t}(\lambda)\right]=0
$$

where $\mathbf{x}_{t}$ is the set of instruments. To avoid a problem of over-fitting (weak instrument issues) we choose parsimonious instrument matrices that yield a satisfactory statistic for the overidentification test, and then test how the various alternative assumptions discussed affect the estimate.

A minimum requirement for a reasonable model fit, as in all time-series estimations, is that the residuals should be white noise, so we provide the standard Bartlett's Cumulative Periodogram B-tests and Portmanteau Q-tests for residual autocorrelation. 
We used Stata 11's built in iterated GMM procedure to optimize the moment weighting matrix, with heteroskedasticity and autocorrelation robust Newey-West standard errors. No numerical problems or anomalies occurred during the estimation.

\subsection{MODEL SELECTION AND ESTIMATION RESULTS}

Since we have a large number of potential specifications (we investigate 144 in total), we need some criteria to select the adequate models. We use the following:

\section{Instrument set validity}

We are estimating one parameter with potentially as many as 21 moment conditions. We have little preconceived notions of how far into the past instruments will be exogenous and strong enough to be useful. In a highly non-linear model such as this there is a high risk of "overfitting" (Wooldridge, 2001). One way in which "over-fitting" would manifest is in unreasonably high probability values of the test statistic for Hansen's J-test for valid over-identifying restrictions (in brief: As more and more variables are added as instruments to a given regression, even insignificant partial correlations between instruments and endogenous variables accumulate, so that the $\mathrm{p}$-value of valid over-identifying restrictions tends to 1).

We use Hansen's test of over-identifying restrictions for instrument validity. We select all specifications that had a p-value for this test above 0.05 and below 0.8 (the cut-offs were chosen arbitrarily, but the results are not locally sensitive to these choices). This is referred to as the $\mathrm{J}$ test in Table IV.

\section{Data congruency}

A minimum requirement for a time series model of inflation to be plausible is that it should yield white noise errors. Again, a very large instrument set may artificially impose this result on any of the standard tests and pose a risk of data-mining.

We employ two tests for white noise with the following selection criteria:

Bartlett's cumulative periodogram test (referred to as the B test below) and the standard Portmanteau autocorrelation test (referred to as the Q test below). For each of these, we select all models that yield a p-value above 0.05 and below 0.8 . Since the two white noise tests do not 
always agree, we provide a full analysis of the impact of our selection rules applied to different combinations of the tests (see Table IV).

We analyse the implications of using these arbitrary "selection rules" on our estimates graphically via scatterplots of the estimate of the information updating probability (lambda) against the probability value of the respective test along two dimensions: The choice of output gap measure used and the origin of the estimates of expected values of the variables (survey or VAR)

\section{Impact of Output Gap Measure}

First, we note that the test for over-identifications is not correlated with either the output gap measure or the lambda estimate in Figure $\mathrm{II}^{4}$. The estimates we exclude from consideration out of a fear of "over-fitting" does not seem very different from the rest.

\section{Figure II: Scatterplot of lambda estimates against J-test p-values by Output Gap Measure}

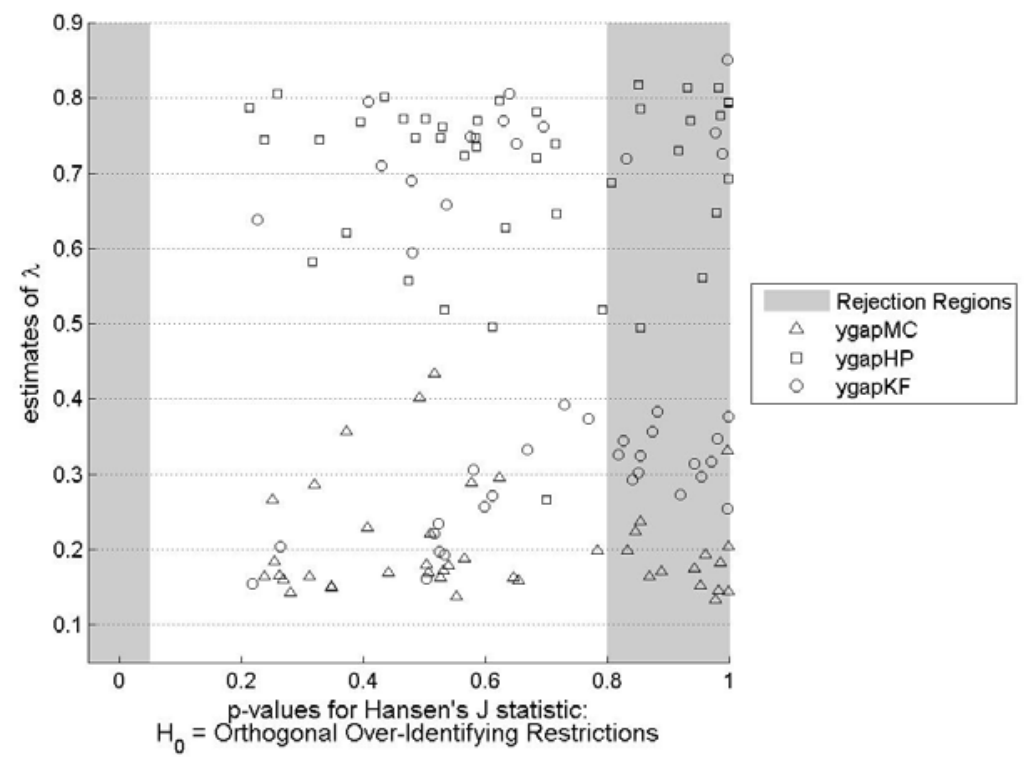

Second, in both auto-correlation tests (Figures III and IV), the models that use ygapMC all yield low estimates for lambda, roughly between 0.15 and 0.45 ; however almost all fall out as

\footnotetext{
${ }^{4}$ Table 4 provides summary measures of the 144 estimates which are represented graphically in figures II to VI.
} 
incongruent with the inflation data according to these tests. Models that use ygapHP most often pass both tests and almost universally yield estimates of lambda between 0.5 and 0.8 . Models that use ygapKF yield estimates in two clusters, mapping with the clusters of estimates generated by the other two measures respectively. Most of the lower lambda estimates using the ygapKF measure fail at least one of the two tests for zero autocorrelation, and hence we feel the evidence is reasonably strong in favour of the underlying parameter according to these methods as being between 0.5 and 0.8 .

Figure III: Scatterplot of lambda estimates against Q-test p-values by Output Gap Measure

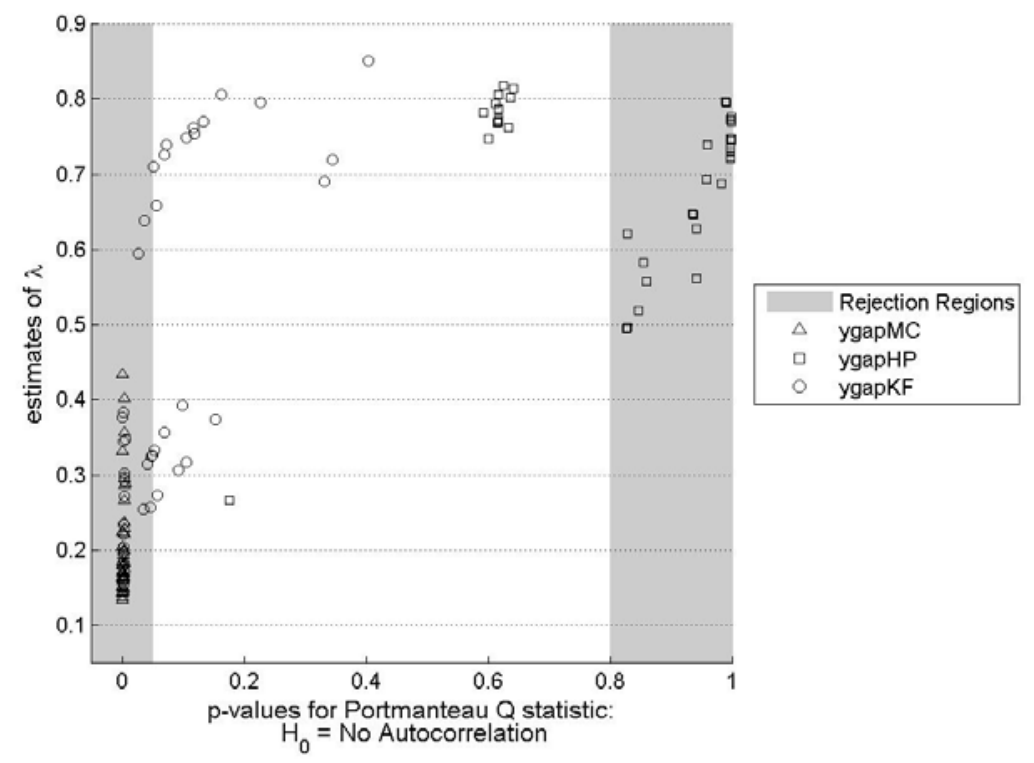

Table IV: Summary of lambda estimates and tests:

\begin{tabular}{|l|c|c|c|c|}
\hline & Pass J and (B or Q) & Pass J and Q & Pass J and B & Pass All \\
\hline \# of models with ygapMC & 2 & 0 & 2 & 0 \\
\hline \# of models with ygapHP & 34 & 13 & 32 & 11 \\
\hline \# of models with ygapKF & 14 & 14 & 1 & 1 \\
\hline $\operatorname{Min}(\boldsymbol{\lambda})$ & 0.27 & 0.27 & 0.29 & 0.69 \\
\hline Mean $(\boldsymbol{\lambda})$ & 0.65 & 0.66 & 0.69 & 0.77 \\
\hline Median $(\boldsymbol{\lambda})$ & 0.74 & 0.76 & 0.74 & 0.77 \\
\hline $\operatorname{Max}(\boldsymbol{\lambda})$ & 0.81 & 0.81 & 0.81 & 0.81 \\
\hline $\operatorname{StdDev}(\boldsymbol{\lambda})$ & 0.16 & 0.19 & 0.12 & 0.03 \\
\hline
\end{tabular}

Impact of various measures of Expectations 
Note that we have three variations: We have inflation expectations constructed from surveys or VAR forecasts as described above. Similarly we have output growth expectations constructed from surveys and forecasts of change in output gap constructed using VAR approach. The SIPC, however, contains expectations of changes in output gap, not output growth. Hence we test three combinations in Figures V and VI: Inflation expectations and output growth expectations both from the survey, with the output growth expectations proxying for the expected change in output gap (labelled "Only Survey" in the figure). The second combination is inflation expectations from the surveys combined with forecasted output gap values from the VAR approach ("Survey and VAR"). The last combination we consider uses forecasts of inflation and the change in output gap constructed by the VAR approach ("Only VAR”).

Figure IV: Scatterplot of lambda estimates against B-test p-values by Output Gap Measure

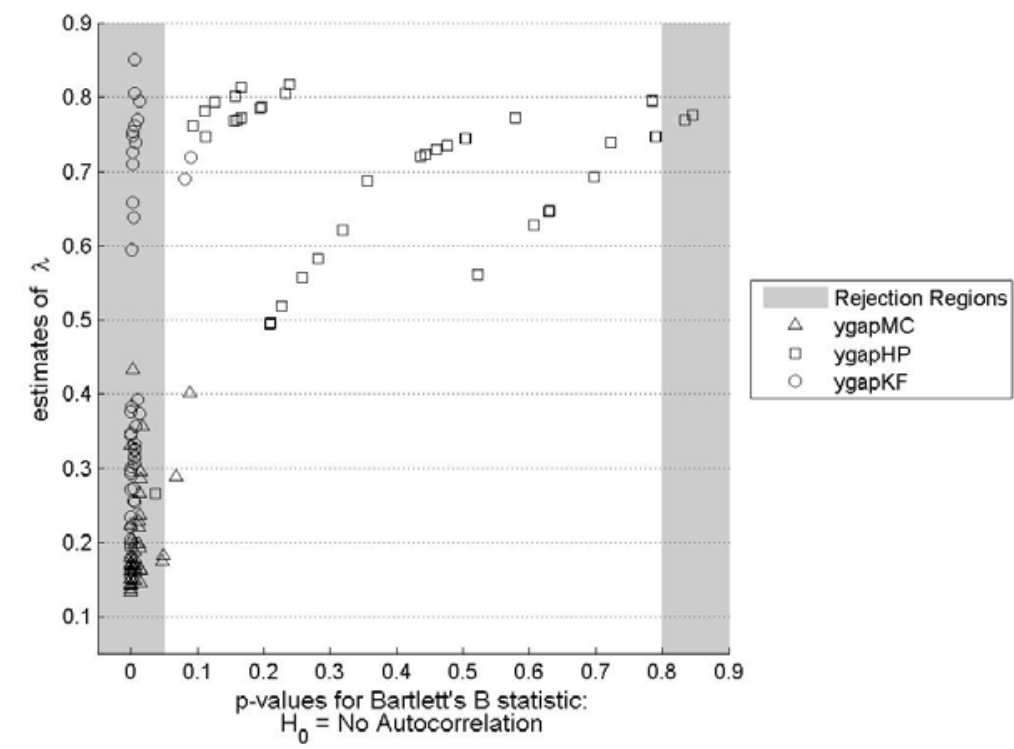

There is no very clear relationship between the estimates of lambda and the proxy for expectations used in the estimation. We present two scatterplots of lambda against p-values for the two auto-correlation tests, only for those estimates that "pass" our J-test criteria described above. 
Figure V: Scatterplot of lambda estimates against Q-test p-values by Expectation Measures

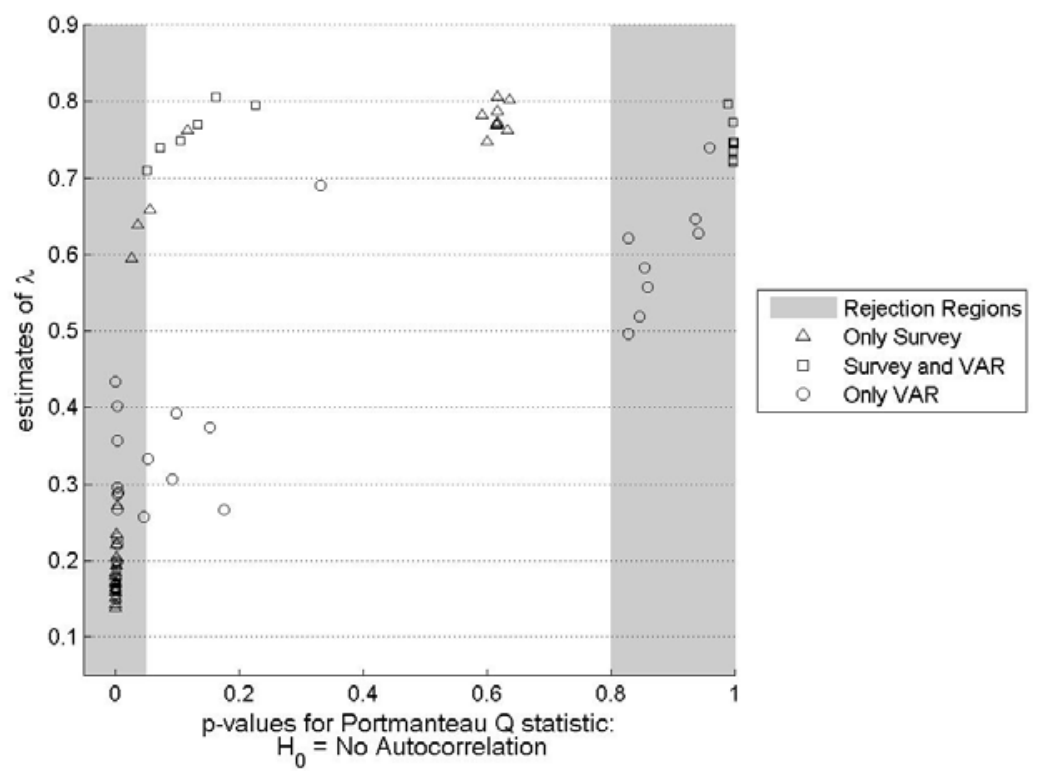

As with most studies of this nature, our results are model dependent, so comparable results estimated in another study using a different methodology is valuable to support these results. In this regard, Reid (2012) explores the process through which South African price setters (the general public) form inflation expectations from a microeconomic perspective.

A combination of estimates of information stickiness from VECM and ARDL models were considered and an estimate of between 0.65 and 0.70 was accepted. The robustness of this estimate was also supported by agent-based models, which were used to estimate the information stickiness from the disaggregated level upward. These results determined from the micro data are comparable with the range of 0.69 to 0.81 estimated for $\lambda$ in this paper. 
Figure VI: Scatterplot of lambda estimates against B-test p-values by Expectation Measures

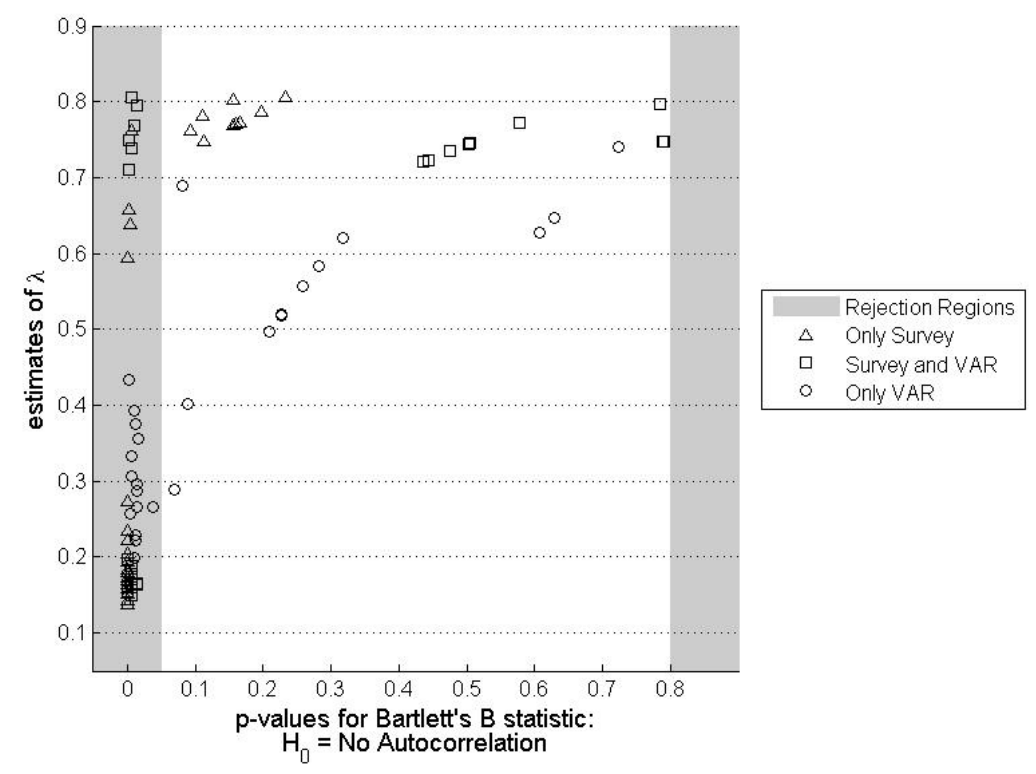

\section{CONCLUSION}

In this paper we have explicitly considered the implications of the choice of inflation expectations and output gap proxies for our model estimation and have used our findings to estimate a sticky information Phillips Curve for South Africa, with an information updating parameter that falls between 0.69 and 0.81 .

We found that the VAR based methodology for constructing forecasts of inflation and output gap gives indistinguishable results from those using survey based expectations. While the theoretical justification of survey based expectations is stronger in principal, the way that the BER presents its expectations questions in South Africa forces the researcher to make ad hoc assumptions that end up yielding expectation terms that are not clearly distinguishable from the VAR based method as proposed by Stock and Watson (2003). Although we understand that the survey questions were set up to match the manner in which the SARB's inflation target was originally 
set $^{5}$, we would like to encourage a reformulation of the questions to facilitate statistical analysis using this data.

It also makes a substantial difference to estimated information rigidity which measure of output gap is used, so the issue cannot be assumed innocuous and deserves detailed attention, and perhaps even a full general equilibrium model. We find that the marginal cost calculation approach is not suited to the South African case. While the results are sensitive to the instrument set in terms of diagnostics, the parameter estimates are quite robust.

Given our consideration of the alternative proxies available for inflation expectations and the output gap, our preferred estimate of $\lambda$ falls between 0.69 and 0.81 . This suggests that the average agent in the economy described by this setup updates her information set every 1.23 to 1.45 quarters, just slightly slower than information on GDP is released. This compares quite favourably with the results of the micro foundations for South Africa by Reid (2012), in which $\lambda$ was estimated to fall in the range $0.65-0.70$.

Given the large number of data and estimation issues we encountered in this project, we have not yet attempted to ascertain which of the SIPC or the NKPC fits the South African data better; we have merely attempted to give as complete and explicit a characterisation of the issues that confronts the researcher wishing to ask these types of questions. We will, in future work, use what we learned here to explore full general equilibrium estimation of the two models with South African data to see if there is evidence in support of one over the other in the spirit of Coibion (2007).

\section{REFERENCES}

AKERLOF, G.A. (2001). Behavioural Macroeconomics and Macroeconomic Behaviour. American Economic Review, Vol 92(3): 411-433.

BALL, L. (1994). Credible Disinflation with Staggered Price Setting. American Economic Review, Vol.84(March): 282-289.

BUREAU FOR ECONOMIC RESEARCH. (2000-2010). Inflation Expectations surveys. http://www.ber.ac.za/surveys/2002.aspx?documenttype=Inflation Expectations

\footnotetext{
${ }^{5}$ When inflation targeting was originally implemented in South Africa, the few targets were specified as calendar year average. From November 2003, the target was applied continuously.
} 
BROOKS, C. (2008). Introductory Econometrics for Finance. Cambridge: Cambridge University Press.

CARROLL, C. 2002. Macroeconomic Expectations of households and Professional Forecasters. Quarterly Journal of Economics, Volume 118, Number 1, February 2003.

CARROLL, C. 2006. The Epidemiology of Macroeconomic Expectations. The Economy as an Evolving Complex System, III: Current Perspectives and Future Directions. Edited by Blume, L.E. and Durlauf, S.N. Oxford: Oxford University Press

CALVO, G.A. (1983). Staggered prices in a utility maximizing framework. Journal of Monetary Economics, Vol. 12 (3): 383-398.

COIBION, O. (2007). Testing the Sticky Information Phillips Curve. College of William and Mary Department of Economics, Working Paper No. 61.

DAVIDSON, R. and MACKINNON, J. (2004). Econometric Theory and Methods. Oxford: Oxford University Press.

DÖPKE, J. DOVERN, J. FRITSCHE, U and SLACALEK, J. (2008). Sticky Information Phillips Curves: European Experience. European Central Bank. Working Paper No. 930.

DU PLESSIS, S and BURGER, R. (2006). A New Keynesian Phillips Curve for South Africa, Presented at the South African Reserve bank Conference: Macroeconomic Policy Challenges for South Africa, 22-24 October 2006.

FURHER and MOORE (1995). Inflation persistence. Quarterly Journal of Economics. Vol. 110(1), February, pp 127-160.

FEDDERKE, J. and SCHALING, E. 2005. Modelling Inflation In South Africa: A Multivariate Cointegration Analysis. South African Journal of Economics. Vol. 73(1), pages 79-92, 03.

FRIEDMAN, M. (1977). Inflation and Unemployment. Journal of Political Economy, Vol.85 (1): 451-472.

FRIEDMAN, M. (1968). The Role of Monetary Policy. American Economic Review Vol.58(1):1-17

FUENTES, R., and MORALES, M. (2007). Measuring TFP: A Latent Variable Approach. Central Bank of Chile Working Papers, 419

GALI, J and GERTLER, M (1999). Inflation Dynamics: A Structural Econometric Analysis. Journal of Monetary Economics, Vol. 44(2):195-222.

GALI, J and LóPEZ-SALIDO, JD (2005). A New Phillips Curve for Spain. Bank of Spain, Working Paper, No. 0109.

GALI, J and LóPEZ-SALIDO, J D (2001). European Inflation Dynamics. European Economic Review. Vol. 45(7):1237-1270.

HAMILTON, J.D. (1994). Time Series Analysis. Princeton University Press, Princeton, New Jersey, USA.

HENDRY, D.F. and NIELSEN, B. (2007). Econometric Modeling: a likelihood approach. Princeton University Press, Princeton, New Jersey, USA.

HODGE, D. (2002). Inflation versus Unemployment in South Africa: Is There a Trade-Off? South African Journal of Economics, Vol. 70, Issue 3.

HUME, D. (1752). Of Money. Reprinted in his Writings on Economics, edited by E.Rotwein. Madison: University of Wisconsin Press. 
KEMP, J.H. (2011). Estimating Potential Output for South Africa: A Production Function Approach. Mimeo, Bureau for Economic Research, Stellenbosch.

KERSHOFF, G. (2000). Measuring Business and Consumer Confidence in South Africa. Mimeo, Bureau for Economic Research, Stellenbosch.

KHAN, H and ZHU, Z. (2006). Estimates of the Sticky-Information Phillips Curve for the United States. Journal of Money, Credit and Banking, Vol. 38(1): 195-207.

KWIATKOWSKI, D., PHILLIPS, P.C.B., SCHMIDT, P. and SHIN, Y. (1992). Testing the null hypothesis of stationarity against the alternative of a unit root: How sure are we that economic time series have a unit root? Journal of Econometrics, Vol 54: 159 - 178.

LUCAS, RE (1995). Nobel lecture: Monetary Neutrality. Journal of Political Economy, Vol.104(4): 661-682.

MANKIW, G. (2001). The Inexorable and Mysterious Tradeoff Between Inflation and Unemployment. Economic Journal, May 2001.

MANKIW, G and REIS, R. (2002). Sticky Information versus Sticky Prices: A proposal to Replace the New Keynesian Phillips Curve. The Quarterly Journal of Economics, Vol. 117(4): 1295-1328.

MANKIW, G and REIS, R. (2003). Sticky Information: A model of Monetary Non neutrality and Structural Slumps. In P. Aghion, R. Frydman, J. Stiglitz and M. Woodford, eds., Knowledge, Information, and Expectations in Modern Macroeconomics: In Honor of Edmund S. Phelps, Princeton, NJ: Princeton University Press, 64-86. .

McCALLUM, B. 1997. Comment on 'Optimisation-based Econometric Framework for Evaluation of Monetary Policy. In NBER Macroeconomics Annual, 1997: 355-359.

ORGANISATION FOR ECONOMIC COOPERATION AND DEVELOPMENT. (2000-2010). OECD statistics. Paris: OECD. Available at: http://www.stats.oecd.org/index.aspx

REID, M.B. (2012). . Inflation Expectations of the Inattentive General Public. Stellenbosch University, Department of Economics, Working Paper Series: 08/2012.

ROSA, C. and VERGA, G. (2006). On the Consistency and Effectiveness of Central Bank Communication: Evidence from the ECB. European Journal of Political Economy, Vol.23(1):146-175.

SBORDONE, AM. (2002). Prices and unit labour costs: A new test of price stickiness. Journal of Monetary Economics, Vol. 49(2): 265-292.

SOUTH AFRICAN RESERVE BANK. (2000-2010). Statistical and Economic Information. Pretoria: South African Reserve Bank. Available at: http://www.resbank.co.za

STOCK, J.H and WATSON, M. W. (2003). Forecasting Output and Inflation: The Role of Asset Prices. Journal of Economic Literature, Vol.XLI(Sept): 788-829.

YU, D. (2007). The comparability of the Statistics South Africa October household surveys and Labour Force Surveys. Stellenbosch Working Paper, 2007/17.

WOOLDRIDGE, J.M. (2001). Econometric Analysis of Cross Section and Panel Data. The MIT Press, Boston, USA. 


\section{APPENDICES}

\section{A1. KALMAN FILTER PRODUCTION FUNCTION ESTIMATION AND EXTRACTION OF OUTPUT GAP ESTIMATE}

\section{Basic Setup}

We estimate a constant returns to scale production function in logarithmic form, assuming that real output $\left(r_{t}\right)$, employment $\left(l_{t}\right)$ and capital stock $\left(k_{t}\right)$ are observable, but that total factor productivity $\left(a_{t}\right)$ is unobserved and follows a random walk with normal innovations $\left(v_{t}\right)$ and no drift. The simple 2 equation system estimated via a Kalman Filter is thus:

$$
\begin{aligned}
& r_{t}=a_{t}+\theta k_{t}+(1-\theta) l_{t}+u_{t} \\
& a_{t}=a_{t-1}+v_{t}
\end{aligned}
$$

We follow Kemp (2011) who uses the methods of Fuentes and Morales (2006) to approximate potential output in the following steps:

1. Use standard Kalman Filter package encoded in Eviews 7 to obtain estimates of the income share of capital $(\hat{\theta})$ as well as of the unobserved sequence of total factor productivity shocks $\left(\left\{a_{t}\right\}\right)$, using observed values of real GDP, capital stock and employed labour force.

2. Assume that "potential output" is given by the estimated production function evaluated at "potential input" values, defined as the HP-filtered trend values of the inputs and estimated productivity shock sequence. For the potential labour sequence, we use the product of smoothed employment rate and smoothed active labour force sequence.

3. The output gap is then the difference between the estimated potential output given potential factors of production.

\section{Data and Challenges}


We use data on real GDP and capital stock from the South African Reserve Bank and employment and labour force data sequence constructed by $\mathrm{Yu}(2007)^{6}$ from regular labour force surveys. Our sample is constrained by the period for which we have reliable labour data: 1995Q4 -2010 Q4.

The estimation with the raw quarterly data gave unreasonably high capital share parameters (around 0.95 when constant returns are imposed) and forced us to take a pragmatic approach.

A leading reason why using quarterly data directly gives bad estimation results of production function is that the GDP and capital stock data are compiled from the same data sources by the same analysts using typical macro data sources, while the labour data comes from surveys. This implies that the measurement error in GDP and capital stock are likely to be highly correlated between these two measures and very different and probably uncorrelated with the measurement error in the labour data. This in turn leads to a spuriously high correlation between GDP and capital stock from as any regression based method is based on partial correlations to some extent. $^{7}$

Figure A1.1 shows that the short term variability of the employment series is very different from that in the other two data sequences (all variables are in index form, $2000=100$, for visual comparison purposes):

\footnotetext{
${ }^{6}$ Derek Yu describes his collation and data cleaning methods in the given reference, but maintains an up to date dataset with new observations as they become available using the same methods, which is the data we use - hence the inconsistency between sample end date and the referenced source date.

${ }^{7}$ Many thanks to Rulof Burger for pointing this out.
} 


\section{Figure A1.1: Real GDP, Capital Stock and Employment indices}

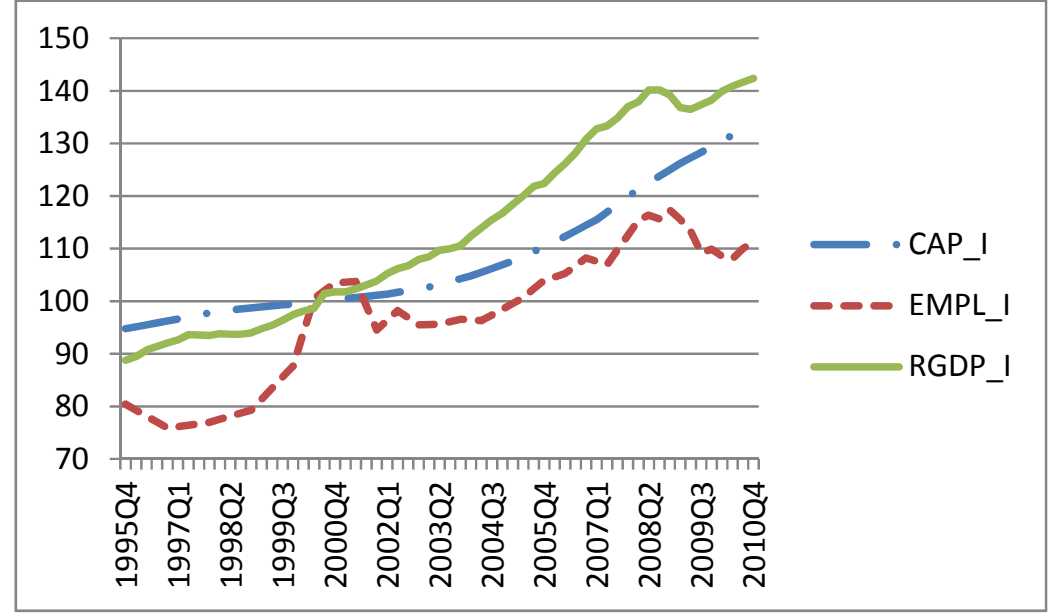

On the assumption that measurement error is a high frequency component, we used the HP-filter on the employment sequence to extract a smoothed version that hopefully is closer to the true underlying employment sequence for the South African economy. However, we did not wish to throw away too much information in the labour sequence by "over-smoothing" the input, we opted for a far lower smoothing parameter that is standard for quarterly data.

Specifically, we arbitrarily chose the following rule to select the HP-filter smoothing parameter: select the lowest smoothing parameter that, when applied to both inputs, yielded a Kalman Filter estimated capital share parameter of lower than 0.6. This bound was chosen as a conservative upper bound to previous capital share estimates that Kemp (2011) summarizes as lying between 0.32 and 0.51 .

The parameter so chosen was 400 (where the default smoothing for quarterly data is 1600 and for annual data 100) and yielded the following smoothed estimate of log employment: 
Figure A1.2: Level, trend and “cycle” of HP-filter smoothed log Employment

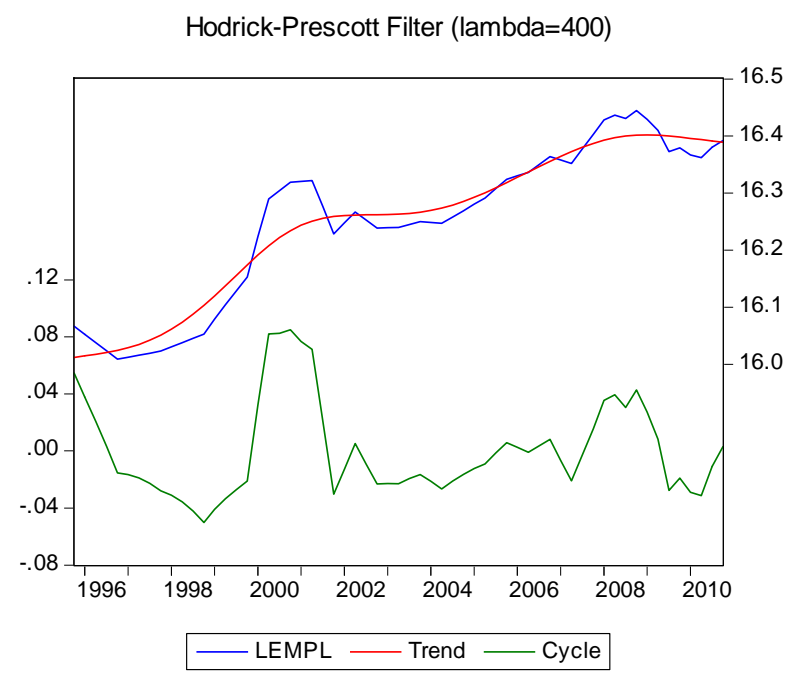

In order to maintain a consistent level of smoothing (motivated by the frequency domain impact of the HP-filter) we again applied an HP filter with smoothing parameter 400 to the estimated total factor productivity to obtain our estimate of "potential total factor productivity" that enters into the potential output calculation (the red line in Figure A1.3 below):

Figure A1.3: Level, trend and “cycle” of HP-filter smoothed log TFP

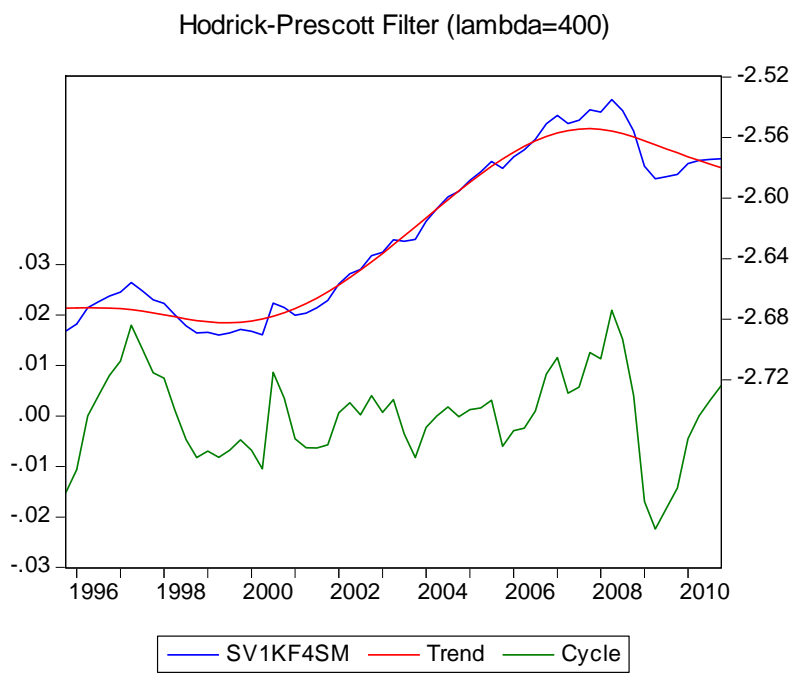

We recognize that this approach is ad hoc, and chose it as a short cut in order to focus on the other data issues involved in the estimation of a Sticky Information Philips curve, as it seems to 
give more "eye-balling consistent" estimates of the output gap over this short period of South African history that the alternative measures.

We will investigate other methods such as instrumental variable approaches to the measurement error in future work where we will estimate a full reduced form version of a general equilibrium model for South Africa that takes all of these aspects into account in a mutually consistent and simultaneous way.

\section{A2. EXTRACTING QUARTER ON QUARTER INFLATION EXPECTATIONS FROM ANNUAL EXPECTATION MEASURED QUARTERLY}

The Bureau of Economic Research (see e.g. BER 2010) conducts quarterly surveys of the inflation and growth expectations of representatives of four sectors of the South African economy: Financial Analysts, Business Executives, representatives of the Trade Union Movement and Households.

Our model requires quarter-on-quarter expectations, while the BER's survey asks for expectations of the inflation for three consecutive calendar years. In this section we establish notation to formalize the relationships between the data available and required and what assumptions are necessary to extract what we require.

If we denote periods (in quarters) by $t$ and the price level (as measured by the CPI index) in quarter $t$ by $P_{t}$ then we can define the following:

\begin{tabular}{cc}
\hline Concept & Notation and definition \\
\hline $\begin{array}{c}\text { Expectations of individual } i \text { conditional on } \\
\text { information available in period } t\end{array}$ & $E_{t}^{i}()$. \\
Year-on-year gross inflation in period $t$ & $\Pi_{t, t-4}=\frac{P_{t}}{P_{t-4}}$ \\
Quarter-on-quarter gross inflation in period $t$ & $\Pi_{t}=\frac{P_{t}}{P_{t-1}}$ \\
& $\Rightarrow \Pi_{t, t-4}=\Pi_{t-3} \Pi_{t-2} \Pi_{t-1} \Pi_{t}$ \\
\hline
\end{tabular}


The first assumption we make is that the average expectation measured in the survey is equivalent to the mathematical definition of the conditional expectation operator (i.e. rational conditional expectations - implying that the only reason that two individuals' expectations may differ is due different information sets). This allows us to ignore the individual superscript on the expectation operators and replace them with their mathematical equilivalent.

Further we assume that when surveyed in quarter $t$, the respondent is perfectly informed of historical output and price level data up to and including that of quarter $t-1$.

Why this is necessary will become clear from the exposition below.

Consider, as an example, the inflation expectation question asked in the each of the quarters of 2009. The question was phrased as follows (answers are the expected net inflation rate, in percentage points):

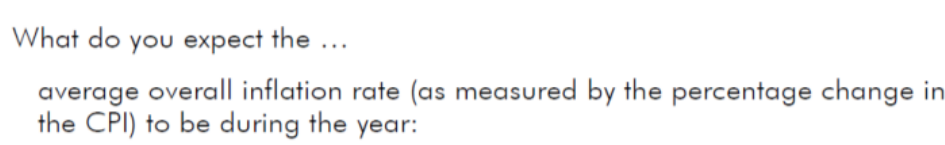

$\begin{aligned} & \text { Average } \\
& 2004-08\end{aligned} 2008 \quad 2009 \quad 2010 \quad 2011$
\begin{tabular}{|c|c|c|c|c|}
\hline 5.6 & 11.5 & & & \\
\hline
\end{tabular}

If we denote the relevant levels of the CPI in quarter $i$ of 2009 as $P_{09 Q i}$, the BER question given above asks for the following expectations (expressed as gross rates $=1+$ net rate):

\begin{tabular}{|c|c|c|c|}
\hline & \multicolumn{4}{|c|}{ Analytical content of answer in columns of the survey question } \\
\hline Quarter of Survey & $\mathbf{2 0 0 9}$ & $\mathbf{2 0 1 0}$ & $\mathbf{2 0 1 1}$ \\
\hline $\mathbf{1}^{\text {st }}$ quarter 2009 & $E_{08 Q 4}\left(\Pi_{08 Q 4,09 Q 4}\right)$ & $E_{08 Q 4}\left(\Pi_{09 Q 4,10 Q 4}\right)$ & $E_{08 Q 4}\left(\Pi_{10 Q 4,11 Q 4}\right)$ \\
\hline $\mathbf{2}^{\text {nd }}$ quarter 2009 & $E_{09 Q 1}\left(\Pi_{08 Q 4,09 Q 4}\right)$ & $E_{09 Q 1}\left(\Pi_{09 Q 4,10 Q 4}\right)$ & $E_{09 Q 1}\left(\Pi_{10 Q 4,11 Q 4}\right)$ \\
\hline $\mathbf{3}^{\text {rd }}$ quarter 2009 & $E_{09 Q 2}\left(\Pi_{08 Q 4,09 Q 4}\right)$ & $E_{09 Q 2}\left(\Pi_{09 Q 4,10 Q 4}\right)$ & $E_{09 Q 2}\left(\Pi_{10 Q 4,11 Q 4}\right)$ \\
\hline $\mathbf{4}^{\text {th }}$ quarter 2009 & $E_{09 Q 3}\left(\Pi_{08 Q 4,09 Q 4}\right)$ & $E_{09 Q 3}\left(\Pi_{09 Q 4,10 Q 4}\right)$ & $E_{09 Q 3}\left(\Pi_{10 Q 4,11 Q 4}\right)$ \\
\hline $\mathbf{1}^{\text {st }}$ quarter 2010 & $N / A$ & $E_{09 Q 4}\left(\Pi_{09 Q 4,10 Q 4}\right)$ & $E_{09 Q 4}\left(\Pi_{10 Q 4,11 Q 4}\right)$ \\
\hline
\end{tabular}

Turning back to general notation we have the following information on the expectation terms directly (in gross terms): 


\begin{tabular}{|c|c|}
\hline Period of Survey & $\begin{array}{c}\text { Expectations of } \\
\text { inflation in year } \\
\text { ending } \\
t+12\end{array}$ \\
\hline$t+1$ & $E_{t}\left(\Pi_{t+8, t+12}\right)$ \\
\hline$t+2$ & $E_{t+1}\left(\Pi_{t+8, t+12}\right)$ \\
\hline$\cdots$ & $\cdots$ \\
\hline$t+12$ & $E_{t+11}\left(\Pi_{t+8, t+12}\right)$ \\
\hline
\end{tabular}

While we technically have twelve quarters of year-on-year expectations available, the assumptions required to convert to a sequence of quarter-on-quarter makes the reliability of constructed expectations far into the future suspect. We therefore restrict ourselves to considering only expectations over a single year - i.e. for every period of the estimation we have only four past expectations of current period inflation to condition on. This leads to the truncation discussed in the main body of this paper.

Given the above outlined nature of the expectations questions, we must deal separately, quarter by quarter for each of the years in our sample. For this purpose let period $t$ refer to the fourth quarter of a representative year. Then we need a different approach to extract each of $E_{t+3}\left(\Pi_{t+4}\right), E_{t+2}\left(\Pi_{t+3}\right), E_{t+1}\left(\Pi_{t+2}\right)$ and $E_{t}\left(\Pi_{t+1}\right)$ respectively.

\section{A2.1 Estimating $E_{t+3}\left(\Pi_{t+4}\right)$}

Starting from the most recent expectation of the inflation in any year, (Thus the question asked in period $t+4$ about $\left.\Pi_{t, t+4}\right)$ we have from the survey:

$$
E_{t+3}\left(\Pi_{t, t+4}\right)=E_{t+3}\left(\Pi_{t+1} \Pi_{t+2} \Pi_{t+3} \Pi_{t+4}\right)=\Pi_{t+1} \Pi_{t+2} \Pi_{t+3} E_{t+3}\left(\Pi_{t+4}\right)
$$

From this we can immediately extract the following estimate of quarter-on-quarter expectation from the survey data combined with officially released CPI data $\left(\frac{P_{t}}{P_{t+3}}\right)$ :

$$
\widehat{E_{t+3}}\left(\Pi_{t+4}\right)=\frac{E_{t+3}\left(\Pi_{t, t+4}\right)}{\Pi_{t+1} \Pi_{t+2} \Pi_{t+3}}=E_{t+3}\left(\Pi_{t, t+4}\right) \frac{P_{t}}{P_{t+3}}
$$

That is, we can directly calculate, without further assumptions, the quarter on quarter inflation expectations for the last quarter of every year in our data-set. 
If we wish to extract the quarter-quarter expectations for the third and earlier quarter of any year, we need to make more assumptions.

\section{A2.2 Estimating earlier terms}

Beliefs about the following object is directly surveyed in the third quarter of every year:

$$
E_{t+2}\left(\Pi_{t, t+4}\right)=E_{t+2}\left(\Pi_{t+1} \Pi_{t+2} \Pi_{t+3} \Pi_{t+4}\right)=\Pi_{t+1} \Pi_{t+2} E_{t+2}\left(\Pi_{t+3} \Pi_{t+4}\right)
$$

This can be rearranged as:

$$
E_{t+2}\left(\Pi_{t+3} \Pi_{t+4}\right)=\frac{E_{t+2}\left(\Pi_{t, t+4}\right)}{\Pi_{t+1} \Pi_{t+2}}
$$

which we can obtain by direct calculation, using survey data for $E_{t+2}\left(\Pi_{t, t+4}\right)$ and official CPI data for $\Pi_{t+1} \Pi_{t+2}$.

By definition (again maintaining the assumption that we are dealing with the standard mathematical operators):

$$
\operatorname{Cov}_{t+2}\left(\Pi_{t+3} \Pi_{t+4}\right)=E_{t+2}\left(\Pi_{t+3} \Pi_{t+4}\right)-E_{t+2}\left(\Pi_{t+3}\right) E_{t+2}\left(\Pi_{t+4}\right)
$$

Rearranging in terms of our expectation term of interest:

$$
E_{t+2}\left(\Pi_{t+3}\right)=\frac{E_{t+2}\left(\Pi_{t+3} \Pi_{t+4}\right)-\operatorname{Cov}_{t+2}\left(\Pi_{t+3} \Pi_{t+4}\right)}{E_{t+2}\left(\Pi_{t+4}\right)}
$$

Thus, in order to extract an estimate of $E_{t+2}\left(\Pi_{t+3}\right)$ we must make an assumption on the views of our respondents on the period $t+2$ conditional covariance between $\Pi_{t+3}$ and $\Pi_{t+4}$ (which we denote $\left.\operatorname{Cov}_{t+2}\left(\Pi_{t+3} \Pi_{t+4}\right)\right)$ as well as the period $t+2$ conditional expectation of $\Pi_{t+4}$. Below we show how we deal with this.

Since we have no direct information on the conditional covariance beliefs of the surveyed respondents (indeed, it would be surprising if any but a handful of the respondents have any experience of the concept at all), we drop this term in the calculations below.

We also have no independent information on $E_{t+2}\left(\Pi_{t+4}\right)$, so we consider the two extreme assumptions: 
Assumption A: $E_{t+2}\left(\Pi_{t+4}\right)=E_{t+2}\left(\Pi_{t+3}\right)$ - i.e. the expected quarter on quarter inflation rate is constant over the two consecutive quarters:

$$
{\widehat{E_{t+2}}}^{A}\left(\Pi_{t+3}\right)=\sqrt{E_{t+2}\left(\Pi_{t+3} \Pi_{t+4}\right)}
$$

Assumption $B$ : $E_{t+2}\left(\Pi_{t+4}\right)=\widehat{E_{t+3}}\left(\Pi_{t+4}\right)$ - i.e. the expectation of the quarter on quarter inflation conditional on information up to two quarters previously is the same as the expectation conditional on information up to one quarter previously (calculated in the previous subsection). In other words, the information revealed in the quarter preceding the one for which expectations are formed is uninformative:

$$
{\widehat{E_{t+2}}}^{B}\left(\Pi_{t+3}\right)=\frac{E_{t+2}\left(\Pi_{t+3} \Pi_{t+4}\right)}{\widehat{E_{t+3}}\left(\Pi_{t+4}\right)}
$$

We take the geometric average of the results from employing the two extreme assumptions, so that our final estimate of the term of interest is:

$$
\widehat{E_{t+2}}\left(\Pi_{t+3}\right)=\sqrt{{\widehat{E_{t+2}}}^{A}\left(\Pi_{t+3}\right){\widehat{E_{t+2}}}^{B}\left(\Pi_{t+3}\right)}
$$

The methods and assumptions used to extract the other terms and are similar, although increasingly tedious and messy, so we omit the details for the sake of brevity. In some cases there were no obvious assumptions available to fill a cell (especially in the many steps ahead forecasts) in which cases we took distance geometric averages of the surrounding observed values. 